\title{
Beehive Strip Dosage Form
}

National Cancer Institute

\section{Source}

National Cancer Institute. Beehive Strip Dosage Form. NCI Thesaurus. Code C149359.

Solid preparation for veterinary use consisting of a matrix impreg nated with active substance(s) that are released by vaporization or physical contact over an extended period of time. Any specific requirements for the placing of the bee-hive strip are described in the product information. 